\title{
Does Disposition Drive Momentum?
}

\author{
Tyler Shumway and Guojun Wu*
}

May 2006

\begin{abstract}
We test the hypothesis that the dispositon effect is a behavioral bias that drives stock price momentum. Using data from a large Shanghai brokerage firm, we estimate the magnitude of the disposition effect for a sample of 13,460 Chinese investors and firms. We find that a large majority of Chinese investors exhibit the disposition effect. An investor's disposition coefficient estimated with one year of data forecasts that investor's disposition effect and investment performance in subsequent years. More disposition-prone investors tend to trade less frequently and in smaller sizes than other investors. While past returns do not forecast future returns in our relatively short sample of Shanghai Stock Exchange stocks, sorting stocks by the net unrealized gains or losses of disposition-prone investors generates a statistically significant winner/loser spread of seven percent per year. Our results suggest that disposition does indeed drive momentum.
\end{abstract}

\footnotetext{
${ }^{*}$ Shumway is at the Ross School of Business, University of Michigan, 701 Tappan Street, Ann Arbor, MI 48109. Phone: 734-763-4129. Email: shumway@umich.edu. Wu is at the Bauer College of Business, University of Houston, Houston, TX 77204. Phone: 713-743-4813. Email: gwu2@uh.edu. We thank Andrea Frazzini (our AFA discussant), Charles Lee, Stefan Nagel, and seminar participants at the 2006 American Finance Association Meetings in Boston, Barclay's Global Investors, Brigham Young University, National University of Singapore, Singapore Management University, Stanford University, University of Virginia, University of Houston and the University of Michigan for comments.
} 


\section{Introduction}

Several researchers document that investors tend to hold assets on which they have experienced paper losses, but they tend to sell assets on which they have experienced gains. Shefrin and Statman (1985) call this the disposition effect, and they explain it with a combination of mental accounting and risk-seeking in losses. Grinblatt and Han (2005) develop a model in which investors with the disposition effect cause momentum in stock prices. We test the hypothesis that the disposition effect is a behavioral bias, or that it is costly to those that exhibit it most strongly. We also test the hypothesis that the disposition effect causes stock price momentum.

The disposition effect has been documented in stock markets by several authors, including Odean (1998) and Grinblatt and Keloharju (2001). These and similar papers make a very convincing case that investors exhibit disposition on average, but it is difficult to show that mental accounting or some other behavioral bias causes disposition. One reasonable alternative explanation holds that investors buy stocks based on private information. After buying, rising stock prices lead investors to conclude that their information has been reflected in prices, but declining prices lead them to conclude that their perceived mispricing has increased. We test the hypothesis that the dispostion effect is a costly behavioral bias by examining the performance and characteristics of the investors that exhibit the most disposition.

Momentum in stock prices is documented by Jegadeesh and Titman (1993) and a number of subsequent authors. Grinblatt and Han (2005) present a relatively simple theory in which momentum is driven by the disposition effect. Intuitively, if disposition-prone investors are holding a stock for which good news is revealed, they will sell their shares as prices rise (as the disposition effect predicts), decreasing any upward pressure on the stock price. Similarly, if disposition-prone investors are holding a stock for which bad news is revealed, they will hold their shares rather than sell on the news, again decreasing any downward pressure on the stock price. If any rational investors trading against the disposition-prone investors do not fully adjust their demands for stocks to account for the disposition bias, prices will take a relatively long time to converge to equilibrium levels following large shocks. One implication of this theory is that the level of unrealized gains or losses among disposition-prone investors is a sufficient statistic for future returns. Past returns 
might predict future returns because they are a noisy proxy for unrealized gains or losses. Given the transaction-level data that we have, we can test this hypothesis directly.

We examine our hypotheses with a large dataset of market transactions on the Shanghai Stock Exchange. Using a hazard model, we estimate the magnitude of the disposition effect individual by individual. Using our investor-level estimates of the disposition effect, we test whether investors show consistent levels of dispostion over time and whether investors that display strong disposition have weaker investment performance than other investors. We also examine several other trading characteristics of investors that display strong disposition, looking for evidence about their relative sophistication. We calculate the unrealized losses or gains for disposition-prone investors in our data, and we regress future returns on past returns and our unrealized gains variables.

We find that a large majority of Chinese investors exhibit the disposition effect. An investor's disposition coefficient estimated with one year of data forecasts that investor's disposition effect in subsequent years. Accounts that correspond to firms or brokerages show less disposition than individual accounts. Individuals with more disposition in one year tend to have worse investment performance in subsequent years. More disposition-prone investors tend to trade less frequently and in smaller sizes than other investors. Surprisingly, more disposition-prone investors tend to hold more diversified portfolios. We interpret our evidence as consistent with the hypothesis that disposition is a costly behavioral bias.

Turning to momentum results, past returns do not forecast future returns in our relatively short sample of Shanghai Stock Exchange stocks. Performing the same test using CRSP data reveals that past returns do not predict future returns among U.S. stocks during our sample period. However, sorting Chinese stocks by the net unrealized gains or losses of all investors in our dataset generates a statistically and economically significant "momentum-like" effect. Sorting stocks by the unrealized gains of particularly disposition-prone investors generates a winner/loser spread of seven percent per year. We think this evidence is consistent with the hypothesis that disposition drives momentum.

The next section discusses in more detail the hypotheses that we test and our methods for testing them. The following section describes our data and compares it with other individual investor datasets. Section III presents the results of our statistical tests, and section IV concludes. 


\section{Hypotheses and Methods}

We want to test the hypotheses that the disposition effect is a costly behavioral bias and that it drives momentum. This section describes and motivates our hypotheses in more detail. It also describes the methods of our statistical tests.

\section{A. Measuring Disposition}

The most direct ways to examine the potential cost and effect of disposition require estimating the extent to which individuals in our data exhibit the effect. Previous researchers have measured the dispositon effect in a number of ways. Odean (1998) compares the proportion of losses realized to the proportion of gains realized by a large sample of investors at a discount brokerage firm. Grinblatt and Keloharju (2001) model the decision to sell or hold each stock in an investor's portfolio by estimating a logit model that includes each position on each day that an account sells any security as an observation. Days in which an account does not trade are dropped from their analysis. As Feng and Seasholes (2005) point out, a potential problem with these and similar approaches is that they may give incorrect inferences in cases in which capital gains or losses vary over time. Consider, for example, a security purchase that results in an immediate capital gain, which is reversed only after a relatively long period of time. Figure 1 shows such a situation with a simulated stock return path. If the investor holding this position sells the security immediately after the gain becomes a loss (on day 40 in Figure 1), it will appear that the investor wanted to avoid realizing a loss even though the opposite might be more correct.

Like Feng and Seasholes (2005), we estimate the disposition effect with a Cox proportional hazard model with time-varying covariates. Our time-varying covariates include daily observations on some market-wide variables (5-day moving averages of return, return squared, and RMB volume) and daily observations on whether each position corresponds to a capital loss or gain. One advantage of our method is that the hazard model, which directly models the stock holding period, implicitly considers the selling versus holding decision each day. Another advantage is that we can easily estimate our model for each account with sufficient trades in our dataset.

Hazard models have been extensively applied in labor economics and other economic fields. 
Proportional hazard models make the assumption that the hazard rate, $\lambda(t)$, or the probability of liquidation at time $t$ conditional on being held until time $t$ is,

$$
\lambda(t)=\phi(t)\left[\exp \left(x(t)^{\prime} \beta\right)\right]
$$

where $\phi(t)$ is referred to as the "baseline" hazard rate and the term $\exp \left(x(t)^{\prime} \beta\right)$, which might be called the "relative" hazard rate, allows the expected holding time to vary across accounts and positions according to their covariates, $x(t)$. The baseline hazard rate is common to all the trades in the sample. In hazard models estimated by investor, the baseline hazard rate describes the typical holding period of just one investor. Note that in this model the covariates may vary with time. As mentioned above, each of our covariates changes daily. The Cox proportional hazard model does not impose any structure on the baseline hazard, $\phi(t)$. Cox's partial likelihood estimator

provides a way of estimating $\beta$ without requiring estimates of $\phi(t)$. It can also handle censoring of observations, which is one of the features of the data. Details about estimating the proportional hazard model can be found in many places, including in Cox and Oakes (1984).

It is natural to ask whether either portfolio rebalancing or tax-loss selling will influence the results of our disposition effect estimation. With respect to portfolio rebalancing, our investors appear to hold rather undiversified portfolios, making rebalancing an unlikely concern. We will give more evidence about the average level of diversification later in the text. With respect to tax-loss selling, there is no capital gains tax in China. In fact, the only significant tax that the investors in our data have to pay is a transactions tax that is equal to twenty basis points per trade. Thus, it is quite unlikely that either taxes or rebalancing are significant motives for trade in our data. The structure and tax environment of the Shanghai market is described in more detail in Seasholes and $\mathrm{Wu}(2005)$.

\section{B. Testing for Bias}

Some of the best existing evidence about the nature of the disposition effect is Odean (1998). Odean shows that on average, individual investors at a large U.S. discount brokerage firm exhibit the disposition effect. He also shows that on average, the trades that these investors place appear 
irrational. The stocks that individual investors buy tend to underperform the stocks that they sell. Feng and Seasholes (2005) show that investors display less disposition over time, implying that they learn to avoid the disposition effect. Dhar and Zhu (2002) show that relatively unsophisticated investors are particularly likely to exhibit the disposition effect. However, using essentially the same data as Odean (1998), Coval, Hirshleifer and Shumway (2005) show that while on average the performance of individual investors may be poor, some individual investors consistently outperform the market on a risk-adjusted basis. Thus, it is possible that the investors that most strongly display the disposition effect are informed investors. We exploit our ability to estimate the disposition effect at the account level to examine this possibility.

One necessary condition for disposition to be a behavioral bias is that disposition is a stable, predictable attribute of a particular investor. In the theory of Grinblatt and Han (2005), there are both disposition-prone investors and rational investors that trade against each other. To be consistent with their story, there should be substantial heterogeneity in the disposition displayed by different investors and any given investor's disposition effect should be more or less constant over time. We examine these features of disposition by testing Hypothesis 1,

Hypothesis 1 There is persistent cross-sectional variation in the degree of the disposition effect among individual investors.

We test this hypothesis by estimating the disposition effect at the investor level in two adjacent time periods. Each set of estimates comes from a completely disjoint dataset. Any trades that are not closed at the end of the first period are considered censored in the model estimated with first period data. Therefore, any trades that are not closed at the end of the first period are completely neglected in the model estimated with second period data. We test Hypothesis 1 by estimating the rank correlation of account-level disposition coefficients over the two periods, and by testing whether the rank correlation is signifcantly different from zero.

Clearly, if informed investors are successful at capturing the value of their information, their investment performance will, on average, be better than that of relatively uninformed investors. Thus, if the disposition effect is a manifestation of information trading, those that are particularly disposition-prone should have higher overall stock returns than other investors. If, alternatively, 
disposition is a behavioral bias, particularly disposition-prone investors should have lower overall stock returns than other investors. We test this conjecture with Hypothesis 2,

Hypothesis 2 Investors with high disposition effect coefficients should have relatively poor investment performance.

We test this hypothesis by sorting investors into disposition quintiles based on their coefficients estimated in one period and then examining stock returns by disposition quintile in subsequent periods. To adjust for risk, we truncate long holding periods and estimate average betas and standard deviations of holding period returns by quintile. We also regress holding period returns on a number of control variables and disposition quintile.

While informed investors should have superior investment performance, they should also have other characteristics that we associate with more sophisticated investors. This conjecture motivates our third hypothesis,

Hypothesis 3 Investors with high disposition effect coefficients should appear less financially sophisticated than other investors.

We expect informed investors to have more total wealth than uninformed investors. While we do not observe the wealth of our investors directly, we can observe some quantities that should be correlated with wealth. We examine the average trade size and trade frequency of investors with different disposition quintiles. We also examine the average diversification of different types of investors. Finally, we estimate disposition coefficients for both individuals and corporate accounts. If professionals are more sophisticated than individuals, corporate accounts should display less disposition than individuals.

\section{Disposition and Momentum}

The most significant testable implication of the theory developed in Grinblatt and Han (2005) is that the unrealized gains or losses of disposition-prone investors should be a sufficient statistic for future returns. Conditional on unrealized gains or losses, past returns should have no predictive power for future returns. Grinblatt and Han (2005) test this implication by constructing a proxy for unrealized gains or losses. Their proxy basically compares the current price of a particular 
stock to a volume-weighted past price. Their proxy for unrealized gains appears to drive out any momentum variables in returns forecasting regressions. Frazzini (2005) constructs an unrealized gain variable for mutual funds using data from Spectrum. While Frazzini (2005) cannot measure unrealized gains precisely (Spectrum data are updated at most quarterly), he does find that his unrealized gain variable has significant predictive power for future returns. Given the detailed nature of the data that we have, we can test the implication of Grinblatt and Han (2005) in a more direct way than previous studies.

Before looking at the relation between disposition and momentum, we examine the nature of momentum in our Chinese data. Since past returns should be correlated with unrealized gains or losses, we test Hypothesis 4,

Hypothesis 4 Returns should exhibit momentum - past winners should continue to outperform while past loser underperform.

The Grinblatt and Han (2005) story holds that past returns are a proxy for unrealized gains, so we expect past returns to be weak predictors of future returns. However, given our relatively short sample, it seems likely that we will not have enough statistical power to estimate the momentum relation very precisely.

Given the nature of our account-level transactions data, the most natural way to test the hypothesis of Grinblatt and Han (2005) is to calculate unrealized gains or losses and use them to predict future returns. We directly test Hypothesis 5,

Hypothesis 5 The unrealized gain or loss of all investors in our dataset should be a good predictor of returns.

We construct our measures of unrealized losses or gains by comparing purchase prices to closing prices. We adjust our returns calculations for stock splits and dividends. Once we have calculated the total loss or gain on each open position in the dataset, we take shares-weighted averages of unrealized gains for each stock. Finally, we sort stocks by their average unrealized gain or loss, keeping the top decile of stocks as "winners" and the bottom decile as "losers." We examine the returns to a strategy that is long winners and short losers. 
Finally, the Grinblatt and Han (2005) story stipulates that particularly disposition-prone investors drive momentum. Thus, we measure the unrealized gains or losses of more disposition-prone and less disposition-prone investors separately. Using these two variables, we test our final hypothesis,

Hypothesis 6 The unrealized gain of particularly disposition-prone investors should be a better predictor of returns than the unrealized gain of less disposition-prone investors.

We regress future returns on the winner/loser strategy variable that corresponds to the unrealized gains of more dispostion-prone and less disposition-prone investors.

Having access to account-level data allows us to examine the nature and impact of the disposition effect in novel ways. To the best of our knowledge, researchers have not examined disposition at the investor level before. We believe that we are the first researchers to examine whether disposition is a persistent individual characteristic and to check whether cross-sectional heterogeneity in disposition predicts subsequent performance. We are fairly confident that we are the first researchers to examine the Grinblatt and Han (2005) hypothesis with more and less disposition-prone investors.

\section{Data}

We acquire a transaction-level dataset from a large brokerage firm in the city of Shanghai. We collect all transactions (purchases or sales) that originate from our brokerage firm from the beginning of 2001 to March 12, 2004. A single trading record includes the following variables: transaction date, transaction time, stock ticker, transaction price, size of trade in shares, time the buy order was placed, time the sell order was placed, the trading account number of the buyer, and the trading account number of the seller, the buyer's brokerage office, and the seller's brokerage office. Account numbers allow us to identify and separate buyers and sellers into three groups: individuals, corporations, and brokers. Some summary statistics for our account-level data appear in Panel A of Table 1, and the number of trades and accounts in our data are described in the text below Table 1.

Our dataset contains almost 17 million trades placed by 3.8 million different accounts. We are confident that we have a complete trading record only for those accounts that correspond to our 
Shanghai brokerage firm. The clients of our brokerage traded through 273,945 different accounts and participated in 8.6 million transactions. There are a large number of relatively inactive accounts at our brokerage firm. Of the more than 273 thousand accounts in our data, only 152 thousand placed at least one trade in 2001. For much of our analysis, we require accounts to be fairly active traders. In order to estimate the hazard model for holding period for a particular account, we require the account to have at least seven closed trades (purchase and corresponding sale) within the hazard model estimation period. Of the 152 thousand accounts that placed at least one trade in 2001, 13,460 accounts have at least seven closed trades in 2001. The 13,460 accounts represent our basic sample for much of the analysis in the paper.

The exchange mechanism adopted by the Shanghai Stock Exchange is an anonymous electronic limit order market. Since our data contain both sides of each transaction, we can estimate the total size of our brokerage firm by calculating the frequency with which clients from our firm are matched in the trading process with other clients of our brokerage firm. Our firm's clients are matched with other clients of the same firm 2.09 percent of the time, so we conclude that the trades we examine comprise approximately two percent of the transactions of the Shanghai Stock Exchange.

The average holding period of our investors is 28.5 trading days, but the median holding period is just 8 trading days. We define the holding period as the time between an investor's first purchase of a security and the same investor's first sale of the same security. Figure 2 plots the level of the Shanghai Stock Exchange Composite Index during our sample period. As can be seen from the figure, the average returns of Shanghai Stock Exchange stocks during our sample period is negative, and the average holding period return of our investors is also negative. On average, our investors lose 1.43 percent of the value of their trades over whatever period they hold the stocks in their portfolio. However, the median holding period return is positive at 1.07 percent. Most of the trades that are opened during our sample period are also closed during the period. Only 5.8 percent of all the positions in our dataset are still open at the end of the sample. Translating the average trade size figures into dollar amounts at the official exchange rate of RMB $8.28=\$ 1.00$, the average trade value is $\$ 2624$ and the median trade size is $\$ 1085$.

We also collect daily price data for all stocks traded on the Shanghai Stock Exchange. Our data include a date variable, stock ticker, the stock's opening price, closing price, maximum price, mini- 
mum price, trading volume in shares, trading value in RMB, number of tradable shares outstanding (free float), and total number of shares outstanding. We also collect corresponding information for the major market composite index. Some summary statistics for our price data appear in Panel B of Table 1.

Consistent with the negative average holding period returns in Panel A of Table 1, the average quarterly return of Shanghai stocks is -3.41 percent, with a corresponding standard deviation of 16.65 percent. Most Shanghai stocks have prices between 4 and $30 \mathrm{RMB}$, with an average price of 11.5 RMB. Daily trading volumes are expressed in thousands of RMB, and seem consistent with the average trade values reported above. The median stock, for example, experiences approximately 625 thousand dollars of volume per day.

Comparing our data to other individual investor datasets that are now available to researchers, our data appear to have a few distinct advantages for examining whether disposition drives momentum. Comparing our data to the data available for a large discount brokerage firm in the U.S. (e.g. Odean, 1998), we note that our dataset almost certainly represents a much larger fraction of total market transactions than the discount brokerage firm data. Comparing our data to the data available for investors in Finland (e.g. Grinblatt and Keloharju, 2001), we note that our data include a much broader cross-section of stocks than that available in Finland. Grinblatt and Keloharju use a sample of 88 Finnish stocks to test their hypotheses, while we have approximately 700 stocks for each of our momentum regressions. The biggest limitation of our sample is our relatively short sample length. For the purpose of estimating momentum effects, we have only ten quarters of data to analyze.

\section{Results}

Our results consist of hazard model estimates, average characteristics and performance of investors by disposition quintile, and momentum results. We discuss each set of results in turn. 


\section{A. Hazard Model Estimates}

We report two sets of hazard model estimates. In all of our hazard model estimates, we model the time to the first sale of an existing stock position as a function of the holding period return on the position and other variables. Each of our hazard models is a Cox proportional hazard model, as described in Section I. Our first set of hazard model estimates use the trades of large numbers of traders to estimate one semiparametric relative hazard curve. Our second set of model estimates use the trades of individual traders to estimate much simpler models.

The results of our semiparametric estimation appear in Figure 3. The relative hazard rate is estimated with a hazard model that includes dummy variables for returns in single percentage point bins (e.g. from zero percent to one percent, from one percent to two percent, and so on) which vary from less than -10 percent to 15 percent. We estimate this model with all the trades in our dataset in 2001 (dashed line) and with the trades of frequent traders (with at least seven round-trip trades) in 2001 (solid line). In comparing the two hazard lines plotted, the level of the line is relatively unimportant since the plots represent relative hazards. The shape of the relative hazard curve is of primary interest, and the two curves are remarkably similar in shape. Both curves are relatively flat for negative returns and then increase substantially starting at slightly positive returns. both curves also appear to level off for positive returns above about five percent.

According to the simplest descriptions of the disposition effect, investors are more likely to sell stocks on which they have a positive holding period return than stocks on which they have a negative return. In our relative hazard plot, this type of disposition effect should manifest itself as a step function that is relatively low for negative holding period returns and then jumps to be relatively high for positive returns. While our estimated hazard is not exactly a step function, it is about as close to a step function as a semiparametric estimate is likely to appear. The magnitude of the increase in relative hazards is also remarkable. From Figure 3, it appears that Chinese traders are three or four times more likely to sell out of a position with a holding period return of seven or eight percent than they are to sell out of a position with a return of negative two or three percent. Figure 3 confirms that the behavior of both frequent traders and all traders is quite similar, and that both types of traders exhibit a significant disposition effect.

The results of our individual trader hazard model estimations appear in Table 2. We estimate 
the hazard model for all accounts with at least seven closed trades in 2001 and then we estimate it for all accounts with at least seven closed trades in 2002. The data in Panel A of Table 2 report on coefficient estimates from both years. While the dummy variable that indicates whether unrealized returns are positive or negative appears to be statistically important in the hazard model, the other coefficients do not appear to be important.

Given the structure of our model, a positive coefficient for the indicator variable $I\left(R_{i t}>0\right)$ indicates that an investor has the disposition effect. A coefficient of zero would imply that the unrealized return has no effect on the investor's hazard rate for closing the trade. The median value of this coefficient, $\beta_{d}$, is 1.66. This means that, holding all else equal, the median investor's conditional probability of selling a stock in his portfolio is $\exp (1.66)=5.3$ times higher for stocks with gains than for stocks with losses. The average disposition coefficient for investors in our data is 5.91 and a T-statistic testing the hypothesis that this average is zero is 22.71 . More than ninety percent of the estimated coefficients on the dummy variable are positive. Clearly, the data indicate that the disposition effect is extremely strong among the Chinese investors in our sample.

Looking at the rank correlations in Panel B, it is clear that investors that display the disposition effect in 2001 also tend to display the effect in 2002. The rank correlation of an investor's coefficients in both years is almost 45 percent, which is extremely statistically and economically significant. The rank correlations of the other hazard model coefficients are all statistically significant but they are economically fairly small. Based on the evidence of Table 1, we can conclude that our evidence is quite consistent with Hypothesis 1. Most Chinese investors display the disposition effect, but there appears to be substantial heterogeneity in the magnitude of the effect across individuals. An investor's level of disposition appears to be a stable investor characteristic.

\section{B. Characteristics and Performance}

Interestingly, the disposition effect for corporate and brokerage accounts reported in Table 2 is significantly smaller than that for individuals. While we only have 62 observations on corporate and brokerage accounts, the average $\beta_{d}$ for these accounts is only 2.05 , and the median is just 1.02. Approximately 84 percent of corporate and brokerage accounts have positive values for $\beta_{d}$. This is a startling large quantity, but it is less than the more than ninety percent that holds for 
individuals. These results suggest that investors with more disposition tend to be less sophisticated than investors with less dispositon. Tables 3 through 5 explore this conjecture in much more detail.

Table 3 examines the investment performance of investors by disposition quintile. The table lists a number of summary statistics by disposition quintile, including the average holding period return, the number of days a position is held, the standard deviation of holding period return and the average beta of the stocks that investors hold. Disposition coefficients are calculated using only data from 2001, and investment performance is calculated using only data from 2002 onward. Market betas and other stock and investor characteristics are also calculated using only data from 2001. Given the strength of the disposition effect among these traders, converting holding period returns into equivalent daily or annual returns makes little sense. Therefore, the time over which holding period returns are calculated is either the actual investor's holding period or twenty trading days, whichever is shorter. The row labeled [Holdings $>20$ Days] lists by disposition quintile the percentage of holding period returns that are calculated by marking positions to market after 20 trading days.

The average holding period return of more disposition-prone investors is substantially lower than that of less disposition-prone investors. In fact, average returns are monotonically decreasing in disposition quintiles. Holding period returns are further broken down into market returns over the holding period and stock returns minus the market return over the same period. About half of the underperformance of high disposition coefficient investors appears to be due to market timing, or due to the market return over the holding period. Interestingly, average holding periods are monotonically increasing in disposition quintiles. However, neither the standard deviation of returns nor the average market beta of the stocks held seem to vary much by quintile. More dispositionprone investors are inclined to purchase slightly larger firms than less disposition-prone investors, and the least disposition-prone investors appear to purchase stocks with very high returns over the past 10 days. The buy-day return and sell-day return are listed to explore whether investors with different levels of disposition behave differently with respect to liquidity. There is a small amount of evidence that more disposition-prone investors are more willing to pay the bid-ask spread upon closing a position, but differences in trading styles do not appear to be driving the relative underperformance of more dispositon-prone investors. 
Table 4 reports on the statistical significance of disposition in explaining holding period returns in a regression context. Each holding period return is an observation in the regressions, and the regressions contain disposition quintile, a number of stock characteristics, and finally two other account characteristics. When dispostion quintile is included in this regression as the lone explanatory variable, its coefficient is economically and statistically significant. Going from the lowest disposition quintile to the highest quintile reduces the expected holding period return by $-0.088 * 4=-0.352$, or by thirty-five basis points. In Model 2, including the market beta of the stock has no effect on the coefficient for disposition quintile. In Model 3, including the stocks average squared return, its average daily trading value and its average high price minus low price squared actually makes the coefficient on disposition quintile more negative. In Model 4, including the average 2001 performance of the investor and the investor's average 2001 holding period makes disposition quintile insignificant. These variables are apparently highly correlated with the investor's disposition coefficient. Our evidence appears to be consistent with Hypothesis 2. The investment performance of particularly disposition-prone investors appears to be somewhat worse than that of other investors.

Table 5 describes some other characteristics of investors, primarily proxies for investor wealth, by disposition quintile. Less disposition-prone investors trade in larger sizes and more frequently than more dispositon-prone investors. Trade size and frequency are proxies for investor wealth in our sample. We cannot observe investor wealth, but since margin trades and short sales are restricted in China, wealthier investors can be identified by the magnitude of their trades. The table also reports the average "maximum cash balance" of each type of investor. This quantity is calculated by examining the time-series of each account's trades, calculating the minimum cash balance that the account must have maintained to execute the account's trades on any day corresponding to one or more transactions. We then take the maximum of these cash balance figures as a proxy for the account holder's wealth. Again, this wealth proxy is monotonically decreasing in disposition coefficient quintile, indicating that wealthier investors display less disposition than their less wealthy peers.

More dispositon-prone investors tend to hold more stocks in their portfolios, with average holdings of 3.2 stocks versus 1.6 stocks for the least disposition-prone. Given that the most disposition- 
prone investors have the longest holding periods, the worst performance, and the most diversification, it appears that these investors are only holding onto losers, which make them diversified even though they continue to have abnormally negative returns. This is consistent with the findings of Kumar (2004), who finds that stocks held by less diversified investors have higher average returns than other stocks. Given that corporate and brokerage accounts display less disposition and that less disposition-prone investors are probably wealthier than their more dispostion-prone peers, our evidence is largely consistent with Hypothesis 3. Investors with a particularly strong dispositon effect appear to be less financially sophisticated than other investors.

Overall, it appears that more disposition-prone investors are less financially sophisticated and have worse performance than other investors. This implies that it is relatively unlikely that these investors are informed investors trading in a disposition-like manner to maximize their expected utility. It seems much more likely that the disposition effect is a costly behavioral bias. We explore whether disposition imposes costs on other investors by affecting prices in the next section.

\section{Momentum}

All of our regressions related to momentum are reported in Table 6 . We construct several momentumrelated variables by sorting stocks by the variable of interest (either past returns or unrealized gains) into deciles at the end of each quarter. We then label stocks in the top decile as "winners" and stocks in the bottom decile as "losers." Finally, we construct a variable that is equal to one for winners, minus one for losers, and zero for all other stocks. After defining this variable for each quarter, we regress the returns of all stocks in each quarter on the value of our winner/loser variable at the end of the previous quarter and a series of dummy variables for each quarter in the data. When calculating quarterly stock returns, we drop all stocks that have not traded in previous quarters to avoid unusual returns in the first weeks of IPO stock trading.

In constructing our momentum variable, we sort stocks on returns calculated from the beginning of each quarter until five trading days before the end of the quarter. We drop the last five trading days of returns in order to avoid any bid-ask bounce or extremely short-term price momentum or reversal effects. In constructing our average unrealized gain variables, we take the unrealized gain to be the return on the stock from an investor's purchase date until five days before the end of the 
relevant quarter. We drop stocks that are sold in the five days before the relevant end of quarter date from our calculations. Having unrealized gains at the transaction level, we calculate average unrealized gains at the stock level by multiplying the unrealized gain or loss of each investor in our data by the number of shares the investor purchased. Next, we average this quantity across our investors, and finally we divide the resulting average unrealized RMB loss by the total free float of the stock. This yields something like the shares-weighted average unrealized gain or loss of our investors.

Looking at Table 6, we examine the momentum effect at the Shanghai Stock Exchange in Model 1. During this ten quarter period, the momentum effect in Shanghai goes in the wrong direction. The coefficient on our winner/loser momentum variable is negative, but it is neither statistically nor particularly economically significant. Thus, we are not able to reject Hypothesis 4: there is no apparent momentum in Shanghai data during the period of our study. However, momentum effects may not always be captured by return regressions since returns are noisy proxies for unrealized gains and losses. For example, researchers overall find momentum in the U.S. market, but the momentum effect may not be apparent in every subsample of U.S. returns. As a robustness check, we examine momentum in the U.S. by applying our tests to CRSP data following the same procedure as that for the Shanghai data. As reported in Table 7, we find strong momentum in the U.S. on average, but we find no momentum in the U.S. during our sample period. In fact, the CRSP data sometimes has negative momentum when we look at 10-quarter returns and the ending quarters are in 2003 and 2004. This is consistent with the evidence of Cooper, Gutierrez, and Hameed (2005), which shows that returns to a momentum strategy vary systematically with market returns during the stock sorting period. Therefore, we are not surprised to find that a momentum trading strategy does not appear profitable in our sample.

Model 2 in Table 6 regresses our first average unrealized gain variable on future returns. The unrealized gain variable in Model 2 is calculated with all of the holdings of all of the investors in our dataset that trade through our brokerage. Thus, for example, this variable is calculated by taking the average unrealized gain or loss over about 276 thousand positions at the end of December of 2002. Our unrealized gain variable has a very statistically and economically significant coefficient 
of 1.37 , with an associated T-statistic of $4.49^{1}$. Our regression coefficient can be interpretted as the average return of an equal-weighted portfolio of winners minus the average return of an equalweighted portfolio of losers. Average excess returns of 1.37 percent per quarter translate into an expected annual excess return of 5.59 percent.

Model 3 combines our unrealized gain measure with past returns in one regression. The unrealized gain coefficient becomes larger and more significant while the past returns variable becomes more negative and statistically significant. Apparently, in this particular sample, returns measured over the past quarter are not a particularly good proxy for unrealized gain or loss. Considering the results of Models 2 and 3, our results are consistent with Hypothesis 5. The average unrealized gain or loss of investors is an excellent predictor of future returns. This momentum-like variable even predicts returns over a time period in which momentum itself fails to predict returns.

According to the Grinblatt and Han (2005) model, the returns of particularly disposition-prone investors should be a better predictor of future returns than either past returns or the unrealized gains of all investors. Models 4 through 7 examine this particular prediction by constructing the unrealized gain or loss variable for various subsets of our investor population. In Model 4, we examine the predictive ability of the unrealized gain variable calculated only with the positions of those investors in our dataset that have a positive disposition coefficient. This unrealized gain variable predicts returns quite well, with a coefficient of 1.183 and a T-statistic of 3.88. Including the free float of each stock in the regression (in unreported results) yields qualitatively similar results. Next, we calculate the unrealized gains variable for investors with $\beta_{d}$ above and below the median value of $\beta_{d}$. We regress returns on the associated winner/loser variables in Models 5 through 7 . These variables are calculated with much less data than the unrealized gain variable for all investors described above. For example, while the unrealized gain variable on December 31, 2002 for all investors that trade through our brokerage is based on 276 thousand positions, the unrealized gain variable for investors with above the median disposition is calculated at the same time with only about 31 thousand positions.

Despite being calculated with many fewer positions, Models 5 through 7 show that the unreal-

\footnotetext{
${ }^{1}$ It should be noted that our T-statistic is calculated with one large regression that contains all stock returns over all quarters, with a total sample size of 6834 . If we estimate our regression with a Fama-Macbeth procedure, the coefficient is almost the same but the corresponding T-statistic drops to 1.05 .
} 
ized gain variable of particularly disposition-prone investors is the best predictor of future returns we can construct. The unrealized gain coefficient in Model 5 is the most economically and statistically significant coefficient in Table $5 .^{2}$ The implied portfolio excess return that corresponds with quarterly returns of 1.709 percent is 7.01 percent per year. Including both the winner/loser variable corresponding to above median $\beta_{d}$ investors and that which corresponds to below median $\beta_{d}$ investors makes the latter variable insignificant. This is strong evidence in favor of our sixth hypothesis. It is the unrealized gains of particularly disposition-prone investors that predicts future returns, not past returns or the unrealized gains of all investors.

We should note that while our unrealized gain or loss variable is a powerful predictor of future returns, it is not a publicly observable variable. Therefore any trading strategy designed to exploit this predictability will have to forecast the unrealized gains or losses of disposition-prone investors, a task that does not seem simple. While our results suggest that the momentum effect is driven by the disposition effect, they do not necessarily imply that it is possible to trade profitably on the momentum effect. Lesmond, Schill and Zhou (2004) argue that transactions costs make momentum strategies unprofitable.

\section{Conclusion}

We test whether the disposition effect is a costly behavioral bias and whether it might cause stock price momentum. Our account-level data allow us to perform some powerful tests of the hypotheses that we pose. Our evidence is consistent with the assertion that the disposition effect is a behavioral bias. Investors that exhibit the bias most strongly in one period have inferior investment performance in subsequent periods. They also trade less frequently and in smaller sizes. Accounts associated with corporations or brokerage firms exhibit significantly less disposition than individuals. Thus, disposition appears to be costly to investors.

While past returns do not predict future returns in this sample, past returns also fail to predict future returns in the U.S. during the same period. Consistent with our main hypotheses, the

\footnotetext{
${ }^{2}$ We also estimated regressions of returns on the level of our unrealized gains variables rather than the discretized variable described above (i.e. 1 for top decile, -1 for bottom decile, zero otherwise). The regression results were qualitatively similar, though statistical significance was a little lower. The coefficient corresponding to Model 5 remained statistically significant. To conserve space, we do not report these results in a table.
} 
average unrealized gain or loss of our investors is a good predictor of future returns. Constructing unrealized gain variables with the trades of particularly disposition-prone investors yields the best predictor of future returns that we can generate. We conclude that disposition does appear to drive momentum. 


\section{References}

Coval, Joshua D., David Hirshleifer, and Tyler Shumway, 2005, Can individual investors beat the market? working paper, University of Michigan.

Coval, Joshua D. and Tyler Shumway, 2005, Do behavioral biases affect prices? Journal of Finance $60,1-34$.

Cooper, Michael J., Roberto C. Gutierrez Jr., and Allaudeen Hameed, 2004, Market states and momentum, Journal of Finance 59, 1345-1365.

Cox, David R. and D. Oakes, 1984, Analysis of Survival Data, Chapman and Hall, New York.

Dhar, Ravi, and Ning Zhu, 2002, Up close and Personal: An Individual Level Analysis of the Disposition Effect, working paper, Yale University.

Feng, Lei and Mark S. Seasholes, 2005, Do investor sophistication and trading experience eliminate behavioral biases in financial markets? Review of Finance 9, 305-351.

Frazzini, Andrea, 2005, The disposition effect and under-reaction to news, Journal of Finance, forthcoming.

Grinblatt, Mark and Bing Han, 2005, Prospect theory, mental accounting, and momentum, forthcoming, Journal of Financial Economics.

Grinblatt, Mark and Matti Keloharju, 2001, What makes investors trade? Journal of Finance $56,589-616$.

Jegadeesh, Narasimhan, and Sheridan Titman, 1993, Returns to buying winners and selling losers: Implications for market efficiency, Journal of Finance 48, 65-91.

Kumar, Alok, 2004, Diversification decisions of individual investors and asset prices, working paper, University of Notre Dame.

Lesmond, David, Michael J. Schill, and Chunsheng Zhou, 2004, The illusory nature of momentum profits, Journal of Financial Economics 71, 349-380.

Odean, Terrance, 1998, Are investors reulctant to realize their losses? Journal of Finance 53, $1775-1798$.

Seasholes, Mark S., and Guojun Wu, 2005, Predictable behavior, profits, and attention, working paper, UC Berkeley.

Shefrin, Hersh and Meir Statman, 1985, The disposition to sell winners too early and ride losers too long: Theory and evidence, Journal of Finance 40, 777-91. 
Figure 1: Simulated Stock Return Path

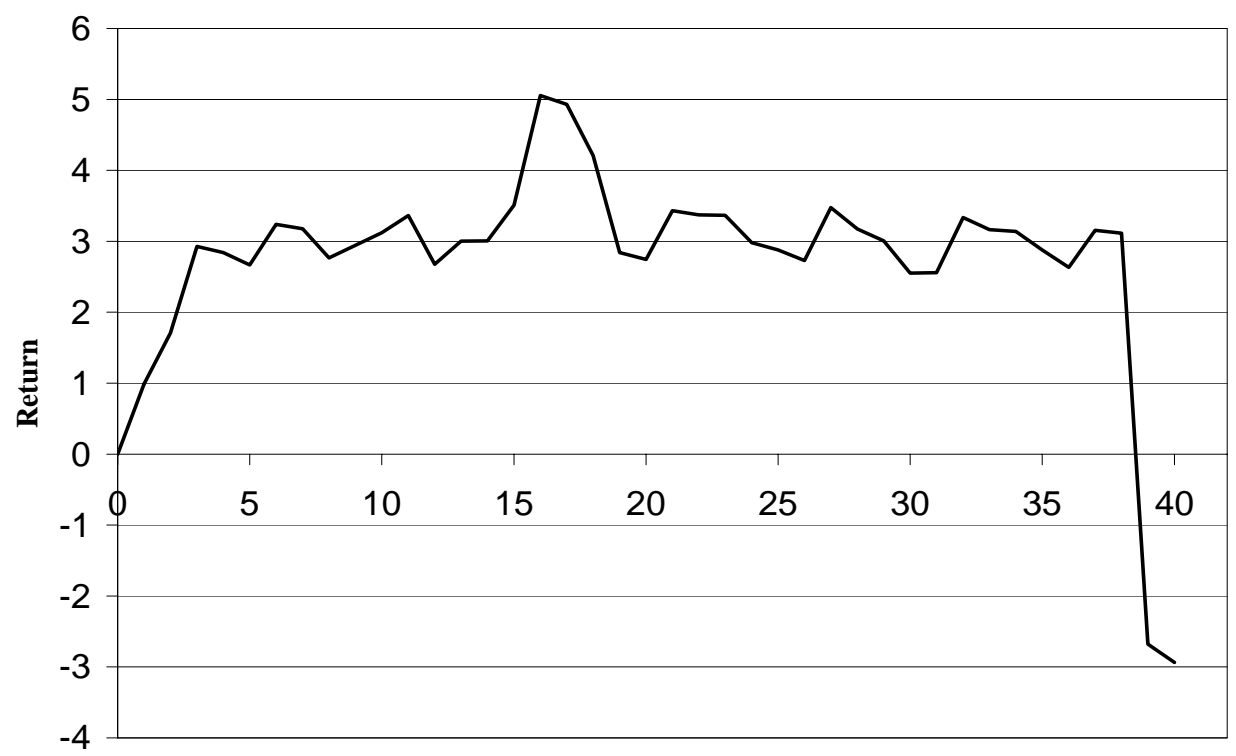

Holding Period (days)

Figure 1 shows a simulated stock return path. It describes a situation where a security purchase results in an immediate capital gain, which is reversed only after a relatively long period of time. In the example presented in section I, day 0 corresponds to the purchase date and day 40 corresponds to the sale date. 


\section{Figure 2: Shanghai Composite Index}

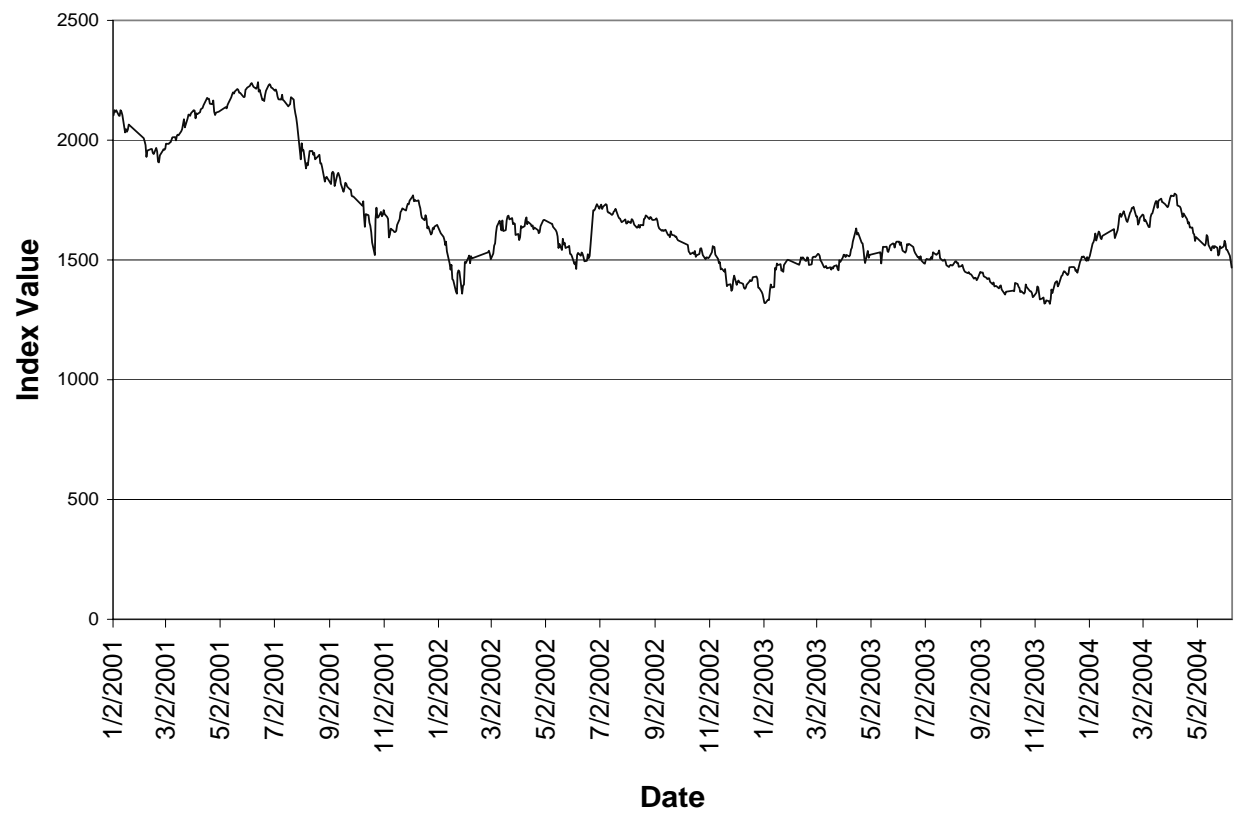

Figure 2 plots the time-series of the Shanghai Stock Exchange Composite Index over the sample period. 
Figure 3: Relative Hazard of Selling a Stock

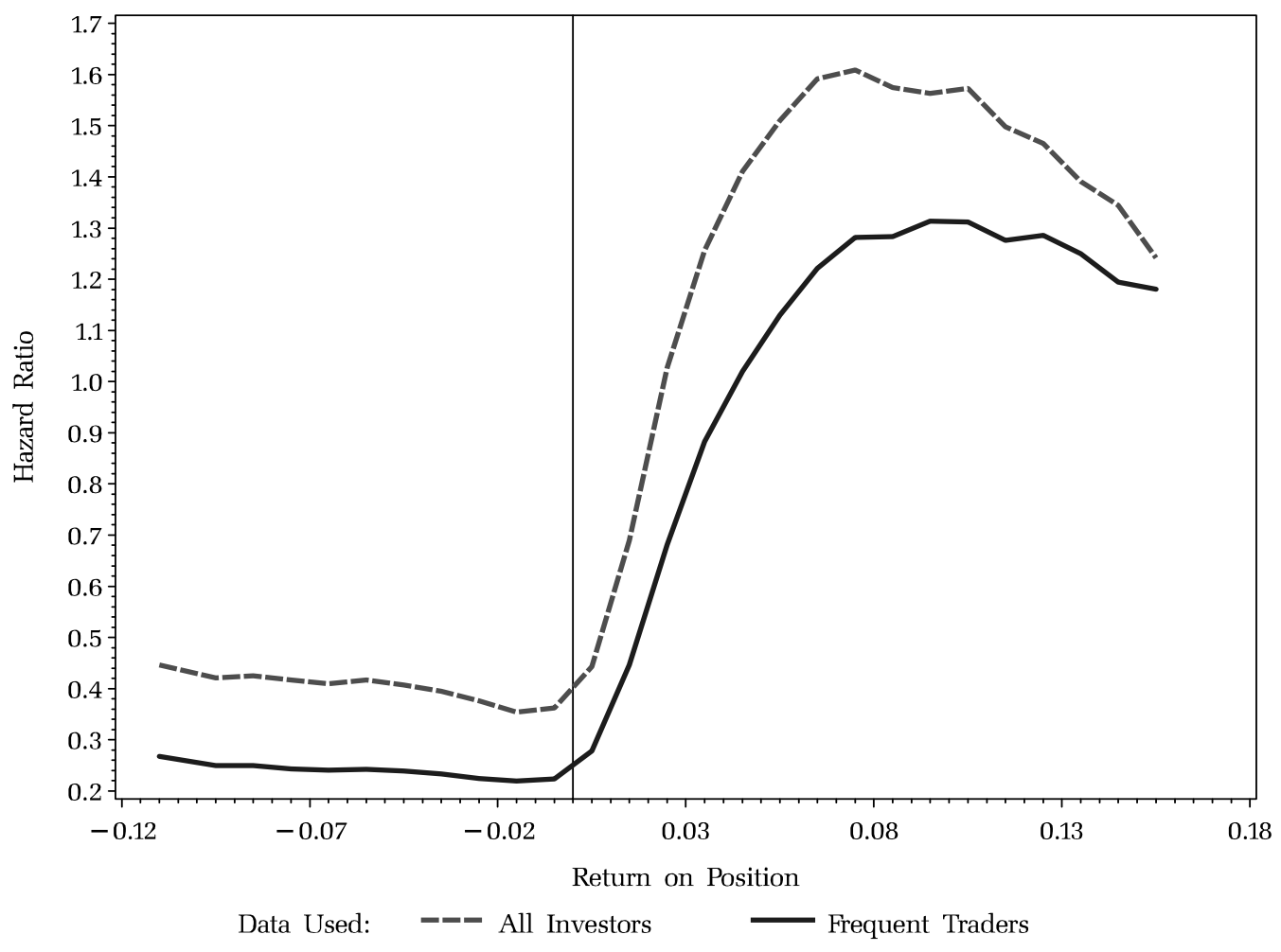

Figure 3 displays the relative hazard rate for selling an existing position as a function of the holding period return on that position. The relative hazard rate is estimated with a Cox proportional hazard model that includes dummy variables for returns in percentage point bins (e.g. from 0 percent to 1 percent) which vary from less than -10 percent to 15 percent. The relative hazard is plotted with all the trades in our data in 2001 (dashed line), and with all the trades of traders with at least seven round-trip trades in 2001 (solid line). 


\section{Table 1: Summary Statistics}

Table 1 provides summary statistics on the sample used throughout the paper. Panel A describes the trades in the account-level data, while Panel B describes the stock-level data. The account-level sample runs from January 2, 2001 through March 12, 2004, while the stock-level data runs over a slightly longer time period. The account-level sample consists of all accounts which complete at least seven trades in 2001 (both purchase and sale). The stock-level data consists of all stocks traded on the Shanghai Stock Exchange. In the account-level data, there are 1,133,194 trades and 13,460 accounts, or about 26 trades per account per year on average. In the stock-level data, there are 817 stocks traded over 819 days, resulting in a total sample size of 557,848 .

Panel A: Account-Level Data

\begin{tabular}{lrrrrr}
\hline Variable & Mean & Std Dev & Median & 1 Percent & 99 Percent \\
\hline Holding Period (days) & 28.5 & 60.4 & 8.0 & 0.0 & 321.0 \\
Return & -1.429 & 10.223 & 1.067 & -37.451 & 17.965 \\
I(Trade Left Open) & 0.058 & 0.235 & 0.000 & 0.000 & 1.000 \\
Trade Size & 21732 & 117683 & 8988 & 1063 & 190270 \\
\hline
\end{tabular}

Panel B: Stock-Level Data

\begin{tabular}{lrrrrr}
\hline Variable & Mean & Std Dev & Median & 1 Percent & 99 Percent \\
\hline Quarterly Return & -3.41 & 16.65 & -5.56 & -33.93 & 45.08 \\
Daily Price & 11.53 & 5.52 & 10.39 & 3.88 & 29.83 \\
Daily RMB Volume (000) & 12946 & 37319 & 5176 & 0 & 122499 \\
\hline
\end{tabular}

\section{Sample Quantities of Interest:}

Total accounts $=3,826,549$

Accounts from our brokerage $(\mathrm{OB})=273,945$

OB accounts with at least 1 trade in $2001=152,010$

OB accounts with at least 7 round-trip trades in $2001=13,460$

Total trades $=16,930,868$

Total OB trades $=8,642,632$

Total trades of $\mathrm{OB}$ traders with $\geq 1$ trade in $2001=6,955,910$

Total trades of OB traders with 7 trades in $2001=1,133,194$

Our brokerage represents about 2.09 percent of all trading in Shanghai stocks 


\section{Table 2: Estimates of the Disposition Effect}

Table 2 reports summary statistics for the coefficient estimates of the Cox proportional hazard model,

$$
\lambda(t)=\phi(t)\left[\exp \left(\beta_{0}+\beta_{d} I\left(r_{i, t}>0\right)+\beta_{v} V_{m, t}+\beta_{s} \sigma_{m, t}+\beta_{r} \bar{r}_{m, t}\right)\right],
$$

where $t$ is the time to position liquidation, $\lambda(t)$ is the hazard rate for liquidation, $\phi(t)$ is referred to as the "baseline" hazard rate and the exponential term allows the hazard rate to vary across trades according to whether the investor has a positive or negative return on the stock, $I\left(r_{i, t}>0\right)$, the average market volume (in Yuan) over the past five trading days, $V_{m, t}$, the average market return squared over the past five trading days, $\sigma_{m, t}$, and the average market return over the past five days, $\bar{r}_{m, t}$. A positive estimate for $\beta_{d}$ is consistent with the disposition effect. The baseline hazard rate, $\phi(t)$, is common to all the trades of one individual. The table reports statistics for individual accounts and corporate accounts separately. The model is estimated for each account that closes at least seven trades in 2001 and for each account that closes at least seven trades in 2002. Panel A reports summary statistics on all estimated coefficients while Panel B reports the rank correlations of each account's coefficient estimates using only data from 2001 and the same coefficients using only data from 2002.

Panel A: Coefficient Estimates

\begin{tabular}{rrrrrcrc}
\hline & \multicolumn{6}{c}{ Individual Investor Accounts in 2001 and 2002 - 23794 Obs } \\
\cline { 3 - 8 } & Mean & Std Dev & T-Stat & Median & \% Positive & 1 Percent & 99 Percent \\
\hline$\beta_{d}$ & 5.91 & 40.12 & 22.71 & 1.66 & 90.30 & -1.82 & 55.87 \\
$\beta_{v}$ & -0.44 & 130.31 & -0.52 & -0.08 & 46.92 & -18.32 & 20.35 \\
$\beta_{s}$ & 0.09 & 7.40 & 1.96 & 0.01 & 61.35 & -0.68 & 1.09 \\
$\beta_{r}$ & 1.31 & 134.61 & 1.51 & 0.08 & 54.00 & -9.85 & 21.82 \\
\hline \multicolumn{7}{c}{ Corporate and Brokerage Accounts in 2001 and 2002 - 62 Obs } \\
\cline { 3 - 8 } & Mean & Std Dev & T-Stat & Median & \% Positive & 1 Percent & 99 Percent \\
\hline$\beta_{d}$ & 2.05 & 4.41 & 3.66 & 1.02 & 83.87 & -0.71 & 24.14 \\
$\beta_{v}$ & -0.10 & 3.19 & -0.23 & 0.04 & 53.22 & -16.23 & 7.02 \\
$\beta_{s}$ & 0.01 & 0.10 & 0.64 & 0.01 & 59.68 & -0.23 & 0.59 \\
$\beta_{r}$ & 0.37 & 1.08 & 2.67 & 0.09 & 59.68 & -1.33 & 4.23 \\
\hline
\end{tabular}

Panel B: Rank Correlations, 2001 Versus 2002

Individuals Only - 5653 Obs

\begin{tabular}{ccc}
\hline & Spearman Corr & P-Value \\
\hline$\beta_{d}$ & 44.58 & 0.0000 \\
$\beta_{v}$ & 6.20 & 0.0000 \\
$\beta_{s}$ & 4.48 & 0.0008 \\
$\beta_{r}$ & 8.59 & 0.0000 \\
\hline
\end{tabular}




\section{Table 3: Predicting Performance with Disposition}

Table 3 examines the cross-sectional relation between disposition and investment performance. All of the statistics reported in Table 3 use disposition coefficients and other statistics estimated with 2001 transactions data to predict investment performance from 2002 through the end of the sample. Each row of the table gives means by disposition quintile. $\beta_{d}$ is the disposition effect coefficient from the hazard model described in Table 2. The average return listed in Row 2 is calculated over either the investor's holding period or the first 20 days of the investors holding period, whichever is shorter.

Means by Disposition Quintile - 328255 Obs

\begin{tabular}{lcrrrc}
\hline Disposition Qunitle: & Quint 1 & \multicolumn{1}{c}{ Quint 2 } & Quint 3 & Quint 4 & Quint 5 \\
\hline Disposition Coefficient $\left(\beta_{d}\right)$ & -0.05 & 0.98 & 1.74 & 2.75 & 17.83 \\
Holding Period (or 20 Day) Return & -0.27 & -0.28 & -0.34 & -0.53 & -0.61 \\
Market Return over Period & 0.05 & 0.03 & 0.00 & -0.02 & -0.11 \\
Return minus Market & -0.32 & -0.31 & -0.34 & -0.51 & -0.50 \\
STD of Holding Period Return & 6.10 & 6.10 & 6.28 & 6.55 & 6.89 \\
Market Beta of Stocks Held & 1.08 & 1.08 & 1.08 & 1.08 & 1.08 \\
Buy Day Return & 0.07 & 0.10 & 0.11 & 0.07 & 0.07 \\
Sell Day Return & 0.00 & -0.04 & -0.04 & -0.03 & -0.03 \\
Holding Period in Days & 31.88 & 36.97 & 48.79 & 63.37 & 85.22 \\
Holdings > 20 Days & 17.88 & 21.21 & 27.18 & 34.29 & 41.85 \\
Period Used for Returns Calculation & 9.29 & 10.80 & 12.26 & 13.90 & 14.99 \\
Return over 10 Days before Purchase & 4.67 & 3.43 & 2.79 & 2.40 & 2.46 \\
Market Float (billions) & 1.70 & 1.75 & 1.76 & 1.79 & 1.84 \\
\hline
\end{tabular}




\section{Table 4: Performance Regressions}

Table 4 gives the results of several performance returns regressions. Each return is measured over the shorter of an actual holding period or the first 20 trading days of an actual holding period. All of the quantities that returns are regressed on are calculated with data from 2001. Returns are regressed against the investor's disposition quintile, the stock's market beta, the stock's average daily high price minus its low price squared, the logarithm of the stock's average daily trade value, the stocks average squared return, the investor's average holding period return, and the investor's average holding period in days, both from 2001. T-statistics are in parentheses.

\section{Returns Regressions - 279558 Obs}

\begin{tabular}{|c|c|c|c|c|}
\hline Variable & Model 1 & Model 2 & Model 3 & Model 4 \\
\hline \multirow[t]{2}{*}{ Intercept } & -0.236 & -0.172 & -6.30 & -0.114 \\
\hline & $(-11.60)$ & $(-5.47)$ & $(-10.73)$ & $(-1.74)$ \\
\hline \multirow[t]{2}{*}{$\beta_{d}$ Rank } & -0.088 & -0.088 & -0.092 & -0.012 \\
\hline & $(-9.48)$ & $(-9.50)$ & $(-9.95)$ & $(-1.22)$ \\
\hline \multirow[t]{2}{*}{$\beta_{i, m}$} & & -1.060 & 0.003 & 0.005 \\
\hline & & $(-2.66)$ & $(0.08)$ & $(0.13)$ \\
\hline \multirow{2}{*}{ Mean $\left(P_{i, t}^{H i}-P_{i, t}^{L o}\right)^{2}$} & & & -0.343 & -0.358 \\
\hline & & & $(-9.76)$ & $(-10.19)$ \\
\hline \multirow[t]{2}{*}{$\ln \left(V_{i}\right)$} & & & 0.017 & 0.190 \\
\hline & & & $(10.66)$ & $(11.05)$ \\
\hline \multirow{2}{*}{ Mean $r_{i, t}^{2}$} & & & -0.922 & -0.939 \\
\hline & & & $(-6.49)$ & $(-6.62)$ \\
\hline \multirow[t]{2}{*}{ Acct. Mean Ret } & & & & 0.237 \\
\hline & & & & $(3.53)$ \\
\hline \multirow[t]{2}{*}{ Acct. Mean Days } & & & & -0.053 \\
\hline & & & & $(-15.58)$ \\
\hline
\end{tabular}




\section{Table 5: Disposition and Investor Characteristics}

Table 5 describes the cross-section of accounts in a little more detail. The table lists average account characteristics for the 13460 accounts with at least seven trades in 2001. Each characteristic is calculated with post-2001 data. The first column gives the average number of stocks held by each account on each of the 10 quarter-ends from the end of 2001 through the end of the first quarter of 2004. The second column lists the average trade size of each type of account, in Yuan. The third column lists the average number of trades placed by each account from the end of 2001 to the end of the sample. The fourth column reports the average maximum cash balance that must have been in each account at one point during the year (in thousands of RMB).

\begin{tabular}{ccccc}
\hline Quint & Stocks Held & Trade Value & Trades & Max Balance \\
\hline 1 & 1.611 & 31333 & 45.18 & 1898.63 \\
2 & 2.232 & 24115 & 50.25 & 1613.52 \\
3 & 2.914 & 19764 & 46.75 & 1326.79 \\
4 & 3.333 & 17792 & 37.99 & 1184.54 \\
5 & 3.205 & 15889 & 23.81 & 726.82 \\
\hline
\end{tabular}




\section{Table 6: Disposition and Momentum}

Table 6 describes the results of seven momentum-style regressions. Each regression forecasts the returns of momentum portfolios measured over three months. Each independent variable is equal to one, zero, or minus one, for each stock in each quarter. The variable called "Momentum," for example, is set to one for stocks in the highest decile of returns in the previous quarter, it is set to minus one for stocks in the lowest decile of returns in the previous quarter, and it is set to zero for all other stocks. Similarly, the unrealized gains or losses variables (UR Gains) are set to one for stocks that rank in the top decile of unrealized gains, minus one for stocks in the bottom decile, which generally have unrealized losses, and zero for all other stocks. The unrealized gain or loss variable is calculated with the positions of all investors in our dataset (All), the positions of all disposition-effect investors $\left(\beta_{d}>0\right)$, the positions of investors with greater than the median disposition $\left(\beta_{d}>\right.$ Med), and the positions of investors with less than the median disposition $\left(\beta_{d}<\right.$ Med). The sample size is 6834 for each regression, corresponding to approximately 683 stocks per quarter over the 10 quarters for which we have data. Each regression also contains (unreported) dummy variables to control for each quarter. T-statistics are reported in parentheses.

Dependent Variable: Quarterly Returns from 2002:1 to 2004:2

\begin{tabular}{|c|c|c|c|c|c|c|c|}
\hline Variable & Model 1 & Model 2 & Model 3 & Model 4 & Model 5 & Model 6 & Model 7 \\
\hline Momentum & $\begin{array}{l}-0.550 \\
(-1.79)\end{array}$ & & $\begin{array}{l}-0.919 \\
(-2.91)\end{array}$ & & & & \\
\hline UR Gain (All) & & $\begin{array}{c}1.370 \\
(4.49)\end{array}$ & $\begin{array}{r}1.582 \\
(5.05)\end{array}$ & & & & \\
\hline UR Gain $\left(\beta_{d}>0\right)$ & & & & $\begin{array}{l}1.183 \\
(3.88)\end{array}$ & & & \\
\hline UR Gain $\left(\beta_{d}>\right.$ Med $)$ & & & & & $\begin{array}{l}1.709 \\
(5.57)\end{array}$ & & $\begin{array}{l}1.494 \\
(4.29)\end{array}$ \\
\hline UR Gain $\left(\beta_{d}<\right.$ Med $)$ & & & & & & $\begin{array}{r}1.160 \\
(3.78) \\
\end{array}$ & $\begin{array}{r}0.457 \\
(1.31) \\
\end{array}$ \\
\hline
\end{tabular}




\section{Table 7: Momentum Regressions Using U.S. Data}

Table 7 describes the results of momentum-style regressions using all CRSP stocks for a sample period of 10 quarters (as in Table 6). Each regression forecasts the returns of momentum portfolios measured over three months using a dummy variable which is equal to one, zero, or minus one, for each stock in each quarter. The variable is set to one for stocks in the highest decile of returns in the previous quarter; it is set to minus one for stocks in the lowest decile of returns in the previous quarter, and it is set to zero for all other stocks.

\begin{tabular}{llrr|rrrr}
\multicolumn{2}{l}{ ending quarter } & beta & t-stat & \multicolumn{2}{l}{ ending quarter } & beta & t-stat \\
\hline 1997 & 1 & 0.017 & 5.641 & 2001 & 1 & 0.037 & 8.712 \\
1997 & 2 & 0.014 & 4.659 & 2001 & 2 & 0.034 & 7.849 \\
1997 & 3 & 0.014 & 4.352 & 2001 & 3 & 0.036 & 8.321 \\
1997 & 4 & 0.017 & 5.453 & 2001 & 4 & 0.022 & 4.959 \\
1998 & 1 & 0.009 & 3.085 & 2002 & 1 & 0.021 & 4.575 \\
1998 & 2 & 0.010 & 3.272 & 2002 & 2 & 0.029 & 6.333 \\
1998 & 3 & 0.010 & 3.304 & 2002 & 3 & 0.019 & 4.410 \\
1998 & 4 & 0.014 & 4.683 & 2002 & 4 & 0.002 & 0.438 \\
1999 & 1 & 0.010 & 3.421 & 2003 & 1 & 0.006 & 1.533 \\
1999 & 2 & 0.009 & 2.741 & 2003 & 2 & -0.010 & -2.426 \\
1999 & 3 & 0.005 & 1.439 & 2003 & 3 & -0.018 & -4.229 \\
1999 & 4 & 0.019 & 5.352 & 2003 & 4 & -0.007 & -1.715 \\
2000 & 1 & 0.029 & 7.072 & 2004 & 1 & -0.010 & -2.384 \\
2000 & 2 & 0.023 & 5.674 & 2004 & 2 & -0.011 & -2.748 \\
2000 & 3 & 0.031 & 7.544 & 2004 & 3 & 0.012 & 3.190 \\
2000 & 4 & 0.047 & 11.273 & 2004 & 4 & 0.012 & 3.214 \\
\hline
\end{tabular}

